\title{
RESEARCH OF CHANNELS OF SUPER CONDUCTIVITY OF THE INTERWELL SPACE
}

\author{
• • p чев, • • трек лов, • • ус инов \\ S. I. Grachev, A. V. Strekalov, A. T. Khusainov
}

юменский индустри льный университет, г.юмень

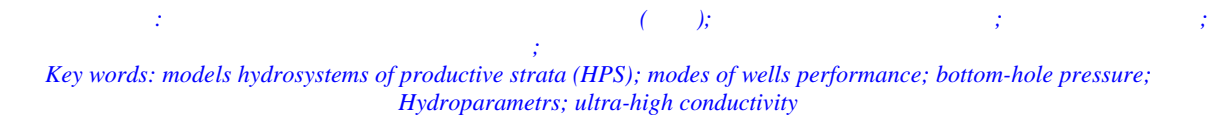

личие в структуре гидросистемы продуктивных пл стов ( ) к н лов со сверхпроводимостью, по мнению с мих второв, проводивших и интерпретирующих результ ты тр ссерных исследов ний, обусловлено, с одной стороны, природной «м кротрещинов тостью», с другой - формиров нием трещин вследствие техногенного воздействия н

бр зов ние или изн ч льное существов ние к н лов сверхпроводимости может ок 3 ться к к положительным, т к и отриц тельным ф ктором р зр ботки и эксплу т ции месторождений в 3 висимости от тех или иных причин.

десь мы не будем ост н влив ться н р ссмотрении технологических методов использов ния или предотвр щения т кой ситу ции, т кже р вновесия положительных и отриц тельных свойств т кого род явления. д нной ст тье т кже не ст вится целью выявить природу т кого явления, скорее предложить более экономичный (в ср внении с тр ссерными исследов ниями или гидродин мическими метод ми) метод идентифик ции к н лов со сверхпроводимостью н основе м тем тической обр ботки д нных о регистрируемых режим х р боты н гнет тельных и добыв ющих скв жин.

к честве прототип предл г емого метод был взят 3 основу идея обр ботки д нных о режим х р боты н гнет тельных скв жин, выск 3 нн я в р боте [1]. д нной ст тье предпол г лся поиск коэффициент прониц емости в зоне воздействия н гнет тельной скв жины н пл ст н основе м тем тической обр ботки д нных дин мики приемистости и з бойного д вления с учетом гидр влического вз имодействия с группой смежных добыв ющих скв жин. дн ко предложенный р нее метод не позволял выявить неоднородность проводимости между скв жин ми, т к к к предпол г лось в к честве неизвестной только величин некой средней прониц емости в окрестности выбр нной н гнет тельной скв жины. 
к пок з л опыт . . трек лов и . . в стьин по использов нию д нного метод , он (метод) ок з лся не применимым в случ е, когд в ф ктической дин мике рост приемистости сопровожд ется п дением з бойного д вления. стественно, согл сно 3 кон м гидромех ники, т кого не может быть при условии относительного постоянств пл стового д вления в зон х между скв жин ми (н середине р сстояния между скв жин ми). огл сно результ т м применения метод [2], для д пт ции модели систем поддерж ния пл стового д вления еверо- окурского месторождения ок $з$ лось, что в 60-70\% н гнет тельных скв жин х н блюд ется подобн я к ртин : рост приемистости во времени периодически сопровожд ется п дением з бойного д вления. p боте [3] выск з но предположение, объясняющее т кого род ситу цию: в н гнет тельных скв жин х, где рост приемистости сопровожд ется п дением 3 бойного д вления, имеет место дест билиз ция пл стового д вления вследствие формиров ния крупных (длинных) трещин в зону отбор или з колонных перетоков.

рименение предл г емого здесь метод не огр ничив ется выявлением только к н лов сверхпроводимости и может быть р сширено для более общих 3 д ч - поиск p спределения прониц емости в зон х воздействия н пл ст исследуемых групп скв жин или месторождения в целом.

к честве основных исходных д нных, необходимых для применения предл г емого метод, используются д нные телеметрии н гнет тельного фонд - дин мик приемистости в виде т булиров нной функции $R(t)$ и устьевого д вления $p_{\text {у }}(t)$ и д нные 3 меров дебитов жидкости по добыв ющему фонду скв жин т кже в виде т булиров нной з висимости - $Q(t)$ (рис. 1$)$.
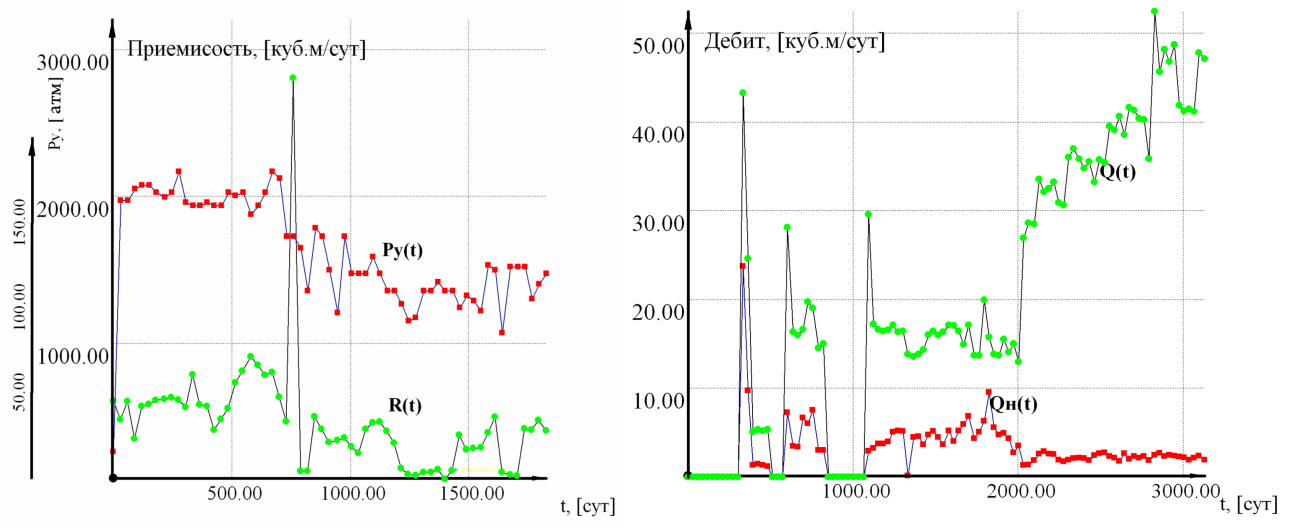

6

ис. 1. римеры исходных дных режимов р боты н гнет тельных и добыв ющих скв жин н- г нского месторождения:

- дин мик устьевого д вления и приемистостин гнет тельной скв. 306; б-дин мик дебитов жидкости и нефти скв. 1748

ля н ч л необходимо пересчит ть устьевые д вления н гнет тельных скв жин в з бойные с учетом гидрост тического переп д д вления до точки з боя и потерь н гидр влическое сопротивление, которое будет з висеть от длины, внутреннего ди мет$\mathrm{p}$, шерохов тости и коэффициент искривления н сосно-компрессорных труб. очность пересчет д вления в основном з висит от точности р счет потерь н гидр влическое сопротивление, одн ко бл год ря существов нию н д нный момент большого количеств экспериментов по з меру потерь д вления при течении воды т кой р счет является довольно точным. ы не будем ост н влив ться н вопрос х р счет потерь д вления при течении в цилиндрических труб х, будем пол г ть дин мику з бойного д вления - $P(t)$ известной после пересчет относительно известного устьевого - $p_{\text {у }}(t)$.

первую очередь необходимо н метить потенци льные линии вз имодействия между н гнет тельными и добыв ющими скв жин ми. ля этого можно использов ть принцип отсечения по р сстоянию (рис. 2 ) или три нгуляционную схему н основ нии метод елоне (рис. 2 в). ричем, если по всем скв жин м имеются з меры 3 бой- 
ного д вления, то можно учитыв ть все линии вз имодействия скв жин (рис. 2 б). дн ко т к к к в большинстве случ ев по добыв ющему фонду т ких з меров очень м ло, их достоверность сомнительн, то будем опир ться только н регистрируемые з бойные д вления в н гнет тельных скв жин х.

н лиз р боты будем проводить для к ждого пл ст в отдельности. ричем н к ждом эт пе в к честве опорной будем выбир ть одну н гнет тельную и смежные с ней (согл сно выбр нным линиям вз имодействия) н гнет тельные и добыв ющие скв жины.

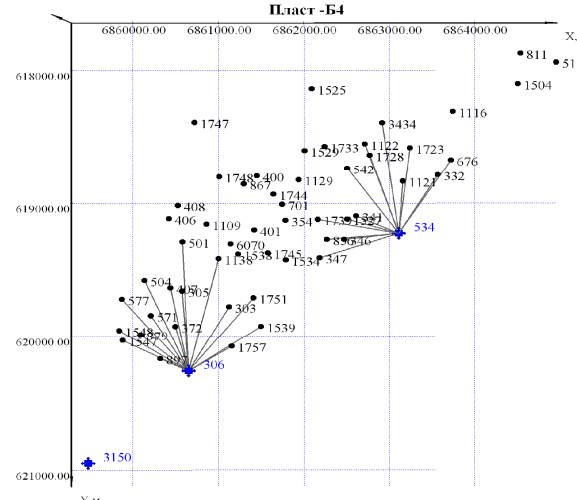

)

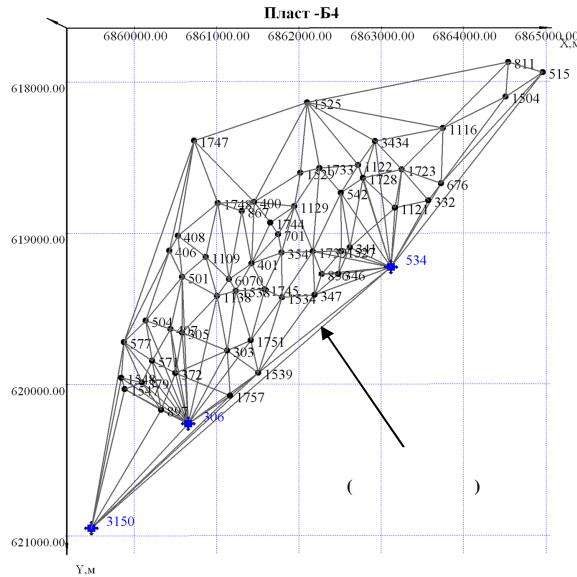

в)

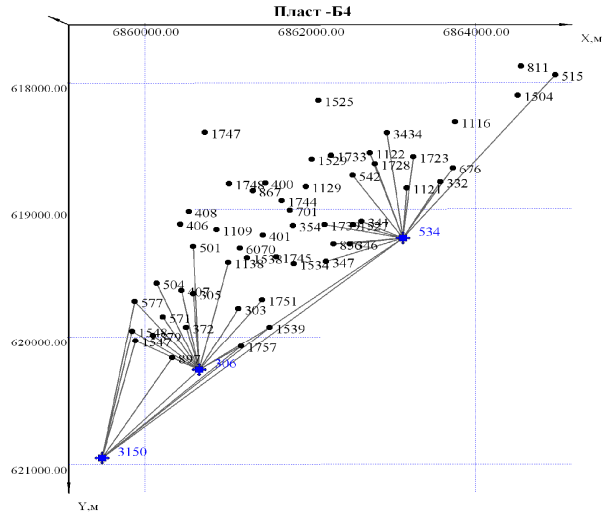

б)

ис. 2. ример выбор потенци льных

линий вз имодействия скв жин со сверхвысокой проводимостью, пл $\mathrm{cm}$

4 н- г нского месторождения:

- р диус вз имовлияния 1000 м;

б-три нгуляция

между н гнет тельными

и добыв ющими скв жин ми;

в - полн я три нгуляция елоне

ким обр зом, из общей м ссы скв жин выделим опорную - одну н гнет тельную скв жину с дин микой $-R_{0}(t), P_{0}(t)$ и $N$ смежных с ней скв жин с дин микой $Q_{i}(t)$. ля смежных с н гнет тельными скв жин величину дебит будем бр ть с отриц тельным зн ком. сновн я идея метод состоит в теоретическом н хождении дин мики з бойного д вления в опорной н гнет тельной скв жине - $p_{0}(t)$ н основ нии дин мики приемистости опорной н гнет тельной скв жины $-R_{0}(t)$ и дин мик дебитов/приемистостей $-Q_{i}(t)$ смежных с ней скв жин. ричем иском я функция $p_{0}(t)$ должн р ссчитыв ться исходя из искомых величин прониц емостей (или пьезопроводностей) по выбр нным линиям вз имодействия скв жин т к, чтобы сумм кв др тов отклонений в точк х ф ктических 3 меров $з$ бойного д вления $-P_{0}(t)$ сводил сь к минимуму:

$$
\sum\left[p_{0}(t)-P_{0}(t)\right]^{2} \rightarrow \min ,
$$


где суммиров ние происходит по всем доступным з мер м з бойного д вления в опорной скв жине.

ля теоретического определения функции $p_{0}(t)$ будем использов ть хорошо известную в подземной гидромех нике з висимость, полученную н основ нии решения ур внения пьезопроводности, для н хождения изменения д вления в точке н блюдения

$$
\Delta p(\Delta t)=\sum_{i=1}^{N} \frac{\Delta q_{i}}{4 \pi \varepsilon} E i\left(\frac{r_{i}^{2}}{4 \chi \Delta t}\right)
$$

где $\Delta p(\Delta t)$ - изменение д вления в точке н блюдения з время $\Delta t ; \varepsilon$ - гидропроводность; $r_{i}-$ р сстояние $i$-ой скв жины до точки н блюдения; $\Delta q_{i}-$ изменение дебит или приемистости з время $\Delta t ; \chi-$ пьезопроводность; $N-$ количество скв жин; $E i$ - интегр льно-пок з тельн я функция.

ссмотрим пример, когд количество выбр нных связей (линий вз имодействия) р вно количеству смежных скв жин $N$, тогд формул (1) изменится подст новкой вместо одной гидропроводности - $\varepsilon$ гидропроводностями по к ждой линии вз имодействия

$$
\varepsilon_{i}=\frac{k_{i} h_{i}}{\mu}
$$

где $k_{i}$ - прониц емость по линии вз имодействия опорной н гнет тельной скв жины и смежной с ней скв жины $i ; h_{i}-$ средняя эффективн я толщин пл ст в зоне между скв жин ми, определяем я по результ т м геофизических исследов ний; $\mu-$ некотор я осредненн я дин мическ я вязкость фильтрующихся нефти и воды в пл стовых условиях.

кже вместо одной пьезопроводности следует подст вить пьезопроводности, вычисляемые для к ждой линии по формуле

$$
\chi_{i}=\frac{k_{i}}{\mu\left(m \beta_{\varkappa}+\beta_{n}\right)},
$$

где $\beta_{ж}$ - осредненный коэффициент сжим емости жидкости; $\beta_{n}$ - коэффициент сжим емости породы; $m$ - коэффициент открытой пористости.

ричем, к к видно из (7-8), метод будет тем точнее, чем выше будет общ я обводненность пл ст .

одст вив (2 и 3$)$ в (1), получим

$$
\Delta p(\Delta t)=\sum_{i=1}^{N} \frac{\mu \Delta q_{i}}{4 \pi k_{i} h_{i}} E i\left(\frac{\mu\left(m \beta_{\varkappa}+\beta_{n}\right) r_{i}^{2}}{4 k_{i} \Delta t}\right),
$$

где $r_{i}-\mathrm{p}$ сстояние между з боями опорной скв жины и смежными с ней.

к к к опорн я н гнет тельн я скв жин ок зыв ет влияние «с м н себя», в формулу (4), помимо влияния режимов смежных скв жин, необходимо доб вить член, отр ж ющий р боту с мой опорной скв жины:

$$
\Delta p(\Delta t)=\frac{\mu_{0} \Delta R_{0}}{4 \pi k_{0} h_{0}} E i\left(\frac{\mu_{0}\left(m \beta_{\varkappa}+\beta_{n}\right) r_{c}^{2}}{4 k_{0} \Delta t}\right)+\sum_{i=1}^{N} \frac{\mu \Delta q_{i}}{4 \pi k_{i} h_{i}} E i\left(\frac{\mu\left(m \beta_{\varkappa}+\beta_{n}\right) r_{i}^{2}}{4 k_{i} \Delta t}\right),
$$

где $k_{0}, h_{0}$ - прониц емость и толщин пл ст в непосредственной близости от з боя опорной н гнет тельной скв жины; $\mu_{0}$ - дин мическ я вязкость н гнет емой воды в пл стовых условиях в опорной н гнет тельной скв жине; $r_{c}-$ приведенный р диус опорной скв жины. 
к к к в формуле (5) р ссчитыв ется дин мик прир щений (изменений) пл стового д вления, то для сопост вления ф ктического з бойного д вления и р счетного необходимо оттолкнуться от н ч льного з мер з бойного д вления $-P_{0}\left(t_{0}\right)$, тогд формул (5) изменится следующим обр зом:

$$
p_{0}(t)=P_{0}\left(t_{0}\right)+\mu_{0} \frac{R_{0}(t)-R_{0}\left(t_{0}\right)}{4 \pi k_{0} h_{0}} E i\left(\frac{\mu_{0}\left(m \beta_{3 c}+\beta_{n}\right) r_{c}^{2}}{4 k_{0}\left(t-t_{0}\right)}\right)+\sum_{i=1}^{N} \mu \frac{Q_{i}(t)-Q_{i}\left(t_{0}\right)_{i}}{4 \pi k_{i} h_{i}} E i\left(\frac{\mu\left(m \beta_{3 \kappa}+\beta_{n}\right) r_{i}^{2}}{4 k_{i}\left(t-t_{0}\right)}\right) .
$$

3 (6) видно, что т к я з висимость будет корректной только при $t>t_{0}$. следствие того, что ди п зоны з меров по всем скв жин м р зличны (т к к к пуск скв жин происходит неодновременно), необходимо т булиров нные функции $R_{0}(t), Q_{\mathrm{i}}(t)$ и $P_{0}(t)$ привести к т кому виду, чтобы при отсутствии з меров и $t<t_{0} R_{0}(t)=0, Q_{\mathrm{i}}(t)=0$, $P_{0}(t)=P_{\text {пл }}$ где $P_{\text {пл }}-$ н ч льное пл стовое д вление.

ким обр зом, в (6) имеет место $N+1$ неизвестных $-k_{0}$, и $k_{i}$ при $i \in[1 . . N], \quad 3$ д ч их поиск относится к 3 д ч м нелинейного прогр ммиров ния для поиск минимум функции относительно неизвестных прониц емостей по линиям вз имодействия скв жин

$$
\Omega\left(k_{0}, k_{1}, \ldots, k_{i}, \ldots, k_{N}\right)=\sum_{j=1}^{M}\left[p_{0}\left(t_{j}\right)-P_{0}\left(t_{j}\right)\right]^{2} \rightarrow \min ,
$$

где $j$ - номер з мер $з$ бойного д вления в опорной скв жине; $t_{j}-$ время, соответствующее з меру $j ; m-$ количество з меров з бойного д вления в опорной н гнет тельной скв жине.

одст вим (6) в (7) и оконч тельно получим

$$
\Omega\left(k_{0}, k_{1}, \ldots, k_{i}, \ldots, k_{N}\right)=\sum_{j=1}^{M}\left[\begin{array}{l}
\left.P_{0}\left(t_{0}\right)+\mu_{0} \frac{R_{0}\left(t_{j}\right)-R_{0}\left(t_{0}\right)}{4 \pi k_{0} h_{0}} E i\left(\frac{\mu_{0}\left(m \beta_{3 c}+\beta_{n}\right) r_{c}^{2}}{4 k_{0}\left(t_{j}-t_{0}\right)}\right)+\right]^{2} \\
+\sum_{i=1}^{N} \mu \frac{Q_{i}\left(t_{j}\right)-Q_{i}\left(t_{0}\right)_{i}}{4 \pi k_{i} h_{i}} E i\left(\frac{\mu\left(m \beta_{\text {эc }}+\beta_{n}\right) r_{i}^{2}}{4 k_{i}\left(t_{j}-t_{0}\right)}\right)-P_{0}\left(t_{j}\right)
\end{array}\right]^{2} \rightarrow \min .
$$

иболее эффективным для решения (8) в пл не ст бильности и скорости решения является метод $L-B F G S$. сож лению, в печ тной публик ции опис ния д нного метод пок нет, поэтому в списке литер туры ук з н ссылк н интернет-источник. етод гр диентного спуск в общем смысле тоже подходит, но является менее н дежным и быстрым, одн ко он тоже может быть использов н для $N<20$.

к видно, результ том решения (8) являются прониц емости по линиям вз имодействия скв жин, что позволяет сдел ть вывод не только о н личии к н лов со сверхвысокой проводимостью, но и о неоднородности пл ст, если т кие к н лы не обн ружив ются. етод позволяет д ть к чественную оценку неоднородности и количественную, то есть величины прониц емостей.

етод теоретического определения дин мики з бойного д вления (или д вления в любой точке н блюдения), соответствующий формул м (1)-(8), имеет огр ничение, связ нное со временем н блюдения, точнее с р зницей времени изменения режим скв жин и времени н блюдения. о есть при м лых пьезопроводностях и длительном н блюдении при р счете дин мики з бойного д вления прохождение импульсов д вления н блюд ться не будет.

ссмотрим более точную версию р счет д вления с учетом произвольных интерв лов 3 мер приемистости, дебит и з бойного д вления. к к к любое изменение отбор или з к чки скв жин должно отр ж ться в изменении д вления в любой точке н блюдения, причем, согл сно гидропроводности и пьзопроводности, в зон х между скв жин ми - источник ми гидр влических возмущений и точкой н блюдения. ля теоретического определения дин мики изменения д вления необходимо учитыв ть длительность выдержки режим отбор или з к чки. 
н логично предыдущим условиям будем пол г ть, что д нные о дин мике отбор или 3 к чки описыв ются множеством з меров р сход жидкости при притоке или оттоке с произвольными интерв л ми времени между з мер ми. следствие того, что величины отбор /з к чки между з мер ми неизвестны, будем пол г ть, что последний 3 мер объемного р сход жидкости соответствует всем предыдущим (до предыдущего 3 мер ). о есть принятый р нее вид з висимости $R(t)$ или $Q(t)$ (см. рис. 2) будет соответствов ть видун рис. 3 . ричем величины дебитов, то есть отбор жидкости следует бр ть со зн ком «-» (рис. 3 в).

зменение приток /отток по скв жине р вносильно подключению новой скв жины в этой же точке пл ст с дебитом или приемистостью, р вной р зности нового и предыдущего зн чений. ричем первый з регистриров нный режим берется к к бсолютное зн чение, все последующие в виде прир щения р сход относительно предыдущего режим .

ким обр зом, формулу (7) следует видоизменить в соответствии с условиями опис ния дин мики отток /приток по скв жин м.

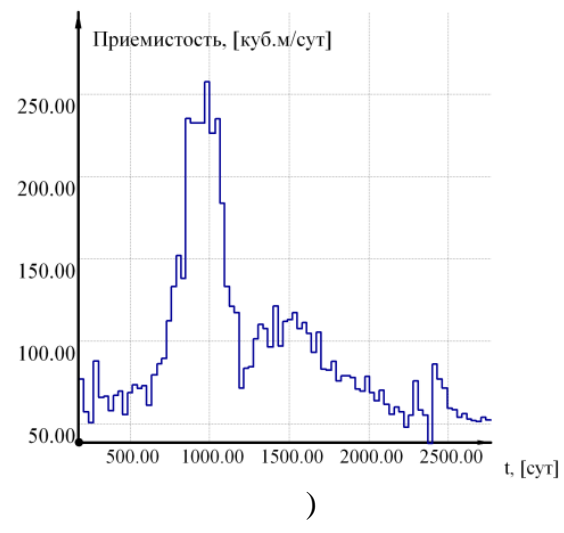

ис. 3. римеры исходных д нных дин мики приемистости и дебит :

- дин мик приемистости $R(t)$;

$\sigma$ - дин мик дебит жиидкости $Q(t)$

(первон ч льный вид); в-преобр зов нный вид дин мики дебит жидкости $Q(t)$

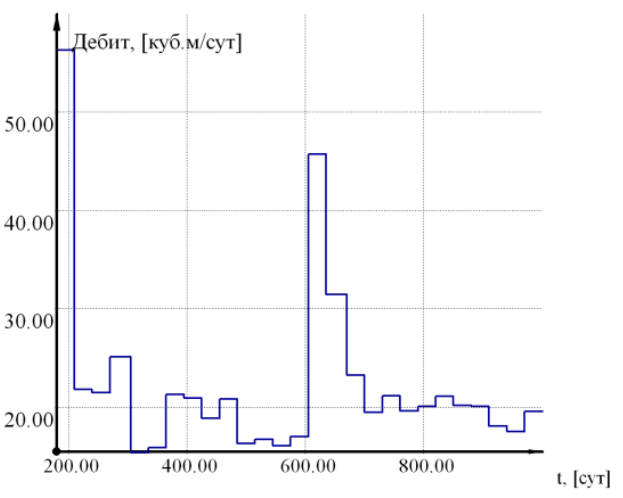

б)

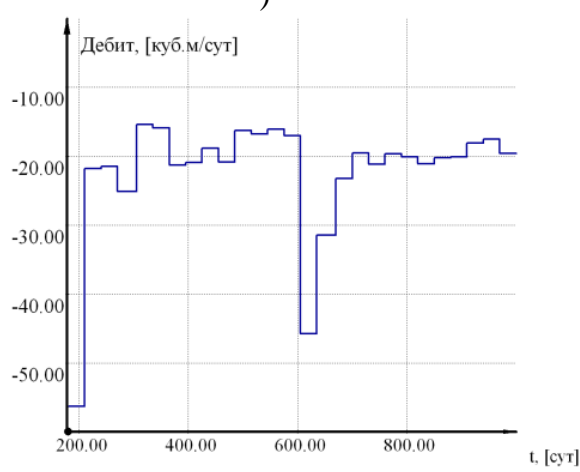

B)

н иболее общем виде, когд отбор по любой $i$-й добыв ющей скв жине $Q_{i}(t)<0$, по любой н гнет тельной $Q_{i}(t)=R_{i}(t)>0$, и зн чение з бойного д вления или д вления в точке н блюдения к моменту $t_{0}$ известно и р вно $P_{m}\left(t_{0}\right)$, з висимость д вления в точке н блюдения будет иметь вид

$$
p_{m}(t)=P_{m}\left(t_{0}\right)+\sum_{i=1}^{N} \Delta p_{i}(t),
$$

где $\Delta p_{i}(t)$ - функция з висимости изменения д вления в точке $m$ вследствие р боты скв жины $i$, котор я будет 3 висеть от р сстояния между з боем $i$-ой скв жины и точкой $m$, пьезопроводности, прониц емости, средней эффективной толщины по линии интерференции (вз имодействия) и т. п. 
К К к время н ч л и конц 3 писи, т кже интерв лы времени между регистрируемыми отбор ми/з к чк ми по к ждой скв жине р зличны, необходимо опис ть дин мики режимов по к ждой скв жине в виде 3 меров приток /отток и соответствующих им точек времени от н ч л р зр ботки или времени с мого р ннего 3 мер :

$$
Q_{i, j}, t_{i, j} \in\left[t_{i, 0} \ldots t_{i, M_{i}-1}\right] \text {, }
$$

где $Q_{i, j}-j$-й $з$ мер приток /отток $\left(\right.$ м $^{3} /$ сут) в скв жине $i$, при $j \in\left[0 \ldots M_{i-1}\right] ; t_{i, j}-j$-ое время (сек) з мер приток /отток в скв жине $i ; M_{i}-$ количество з меров приток /отток в скв жине $i ; t_{i, 0}$ - время первого 3 мер приток /отток в скв жине $i$ $t_{i, M_{i}-1}$ - время последнего з мер приток /отток в скв жине $i$.

ким обр зом, дин мик режимов отбор /з к чки по скв жин м описыв ется дискретной $з$ висимостью $Q_{i, j}\left(t_{i, j}\right)$.

сходя из этого, функция $\Delta p_{i}(t) \mathrm{p}$ ссчитыв ется следующим обр зом. сли $t<t_{i, 0}$, то $\Delta p_{i}(t)=0$; если $t>t_{i, 0}$, то

$$
\Delta p_{i}(t)=\mu \frac{Q_{i, 0}\left(t_{i, 0}\right)}{4 \pi k_{i} h_{i}} E i\left(\frac{\mu\left(m \beta_{\dddot{\prime}}+\beta_{n}\right) r_{i}^{2}}{4 k_{i}\left(t-t_{i, 0}\right)}\right)+\sum_{j=1}^{M_{i}-1} \mu \frac{Q_{i, j}\left(t_{i, j}\right)-Q_{i, j-1}\left(t_{i, j-1}\right)}{4 \pi k_{i} h_{i}} E i\left(\frac{\mu\left(m \beta_{\dddot{ }}+\beta_{n}\right) r_{i}^{2}}{4 k_{i}\left(t-t_{i, j}\right)}\right)
$$

где $r_{i}-$ р сстояние между точкой $m$ и з боем $i$-ой скв жины.

ст льные величины н логичны предыдущему методу.

ричем суммиров ние в д нной формуле следует производить до тех пор, пок $t>t_{i, j}$. читыв я опис нные условия р счет получим оконч тельную з висимость

$$
p_{m}(t)=P_{m}\left(t_{0}\right)+\sum_{i=1}^{N}\left[\begin{array}{l}
\mu \frac{Q_{i, 0}\left(t_{i, 0}\right)}{4 \pi k_{i} h_{i}} E i\left(\frac{\mu\left(m \beta_{w}+\beta_{n}\right) r_{i}^{2}}{4 k_{i}\left(t-t_{i, 0}\right)}\right)+ \\
+\sum_{j=1}^{M_{i}-1} \mu \frac{Q_{i, j}\left(t_{i, j}\right)-Q_{i, j-1}\left(t_{i, j-1}\right)}{4 \pi k_{i} h_{i}} E i\left(\frac{\mu\left(m \beta_{\varkappa}+\beta_{n}\right) r_{i}^{2}}{4 k_{i}\left(t-t_{i, j}\right)}\right)
\end{array}\right] .
$$

рис. 4 пок 3 н р счетн я дин мик изменения д вления $\Delta p_{m}(t)=p_{m}(t)-P_{m}\left(t_{0}\right)-\mathrm{H} \quad \mathrm{p}$ сстоянии 300 м от н гнет тельной скв. 534 н- г нского месторождения посредством использов ния (13).

н логично предыдущему методу, переместив точку н блюдения $m$ н 3 бой выбр нной н гнет тельной скв жины, н пример с индексом $c$, получим целевую функцию, относительно неизвестных прониц емостей в зон х между скв жиной $c$ и $N-1$ ост льных скв жин.

$$
\begin{gathered}
\Omega\left(k_{0}, k_{1}, \ldots, k_{i}, \ldots, k_{N}\right)=\sum_{j=1}^{M_{c}}\left[p_{c}\left(t_{c, j}\right)-P_{c}\left(t_{c, j}\right)\right]^{2}= \\
=\sum_{j=1}^{M_{c}}\left(\begin{array}{c}
\mu \frac{Q_{i, 0}\left(t_{i, 0}\right)}{4 \pi k_{i} h_{i}} E i\left(\frac{\mu\left(m \beta_{э c}+\beta_{n}\right) r_{i}^{2}}{4 k_{i}\left(t-t_{i, 0}\right)}\right)+ \\
\left.P_{c}\left(t_{c, 0}\right)+\sum_{i=1}^{N}\left[\begin{array}{c}
M_{i}-1 \\
+\sum_{j=1}^{\mu} \frac{Q_{i, j}\left(t_{i, j}\right)-Q_{i, j-1}\left(t_{i, j-1}\right)}{4 \pi k_{i} h_{i}} E i\left(\frac{\mu\left(m \beta_{э c}+\beta_{n}\right) r_{i}^{2}}{4 k_{i}\left(t-t_{i, j}\right)}\right)
\end{array}\right)\right)^{2} \rightarrow \min . \\
-P_{c}\left(t_{c, j}\right)
\end{array}\right)
\end{gathered}
$$

ричем, к к видно из (13), в р счетную дин мику з бойного д вления включ ется и с м н гнет тельн я скв жин $c$. ри решении (13), когд $i=c, r_{i}$ берется к к р диус ствол скв жины, н пример $r_{c}=0,1 \mathrm{м}$. 


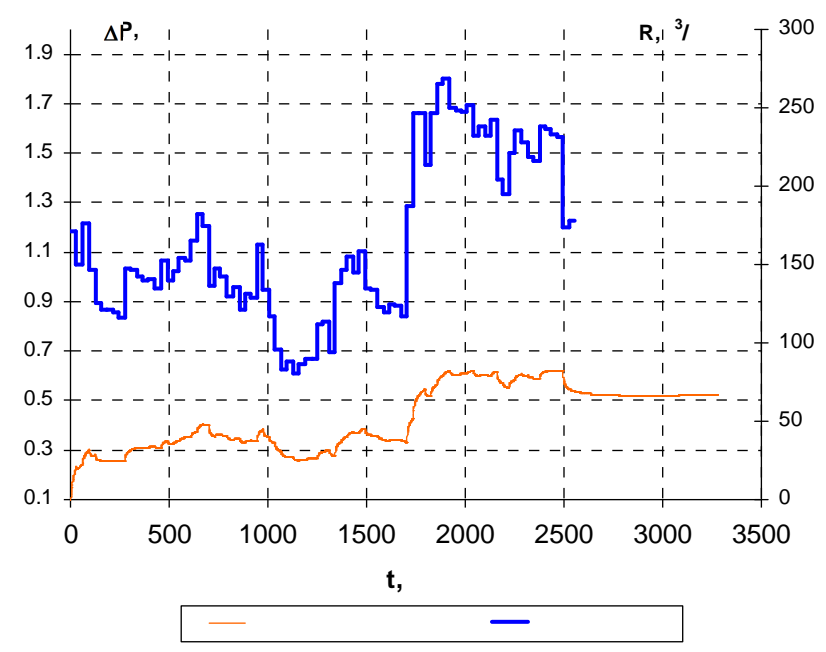

ис. 4. ример р счетной дин мики измененияд вления н р сстоянии 300 м от скв жиины 534, пл ст 4

pис. 5 пок 3 н р счетн я дин мик изменения д вления н р сстоянии 300 м от скв. 534 в более узком ди п зоне, из которой видно, что изменение приемистости скв жины во времени прослежив ется в виде импульсов д вления: пл вный рост или п дение. 3 д нного гр фик т кже видно, что возмущения проходят не мгновенно, то есть р нние возмущения могут доходить до точки н блюдения с з п здыв нием. следствие этого, при текущем п дении приемистости д вление по инерции может продолж ть р сти, но медленнее.

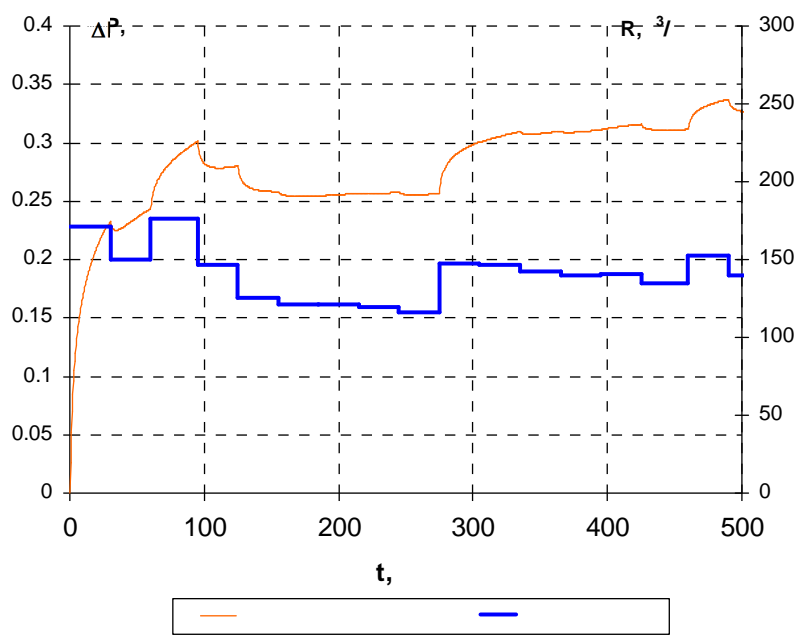

ис. 5. ример р счетной дин мики измененияд влениян р сстоянии 300 м от скв. 534 в более узком ди п зоне, пл $\mathrm{cm} 4$

ешением (13) можно добиться н ибольшего совп дения теоретической и ф ктической дин мик $з$ бойного д вления в исследуемой н гнет тельной скв жине. к к к во всех приведенных з висимостях предпол г ется р венство дин мических вязкостей, открытых пористостей и сжим емостей жидкости и породы, то н йденные коэффициенты прониц емостей $-k_{i}$ будут неизбежно включ ть в себя возможную неоднородность р спределения д нных величин по пл сту, точнее по линиям интерференции скв жин в окрестности исследуемой. 
рис. 6 пок з н пример сопост вления ф ктической и р счетной дин мик з бойного д вления в н гнет тельной скв. 534 без учет влияния скв жин, н ходящихся в окрестности. к видно из гр фиков, р счетн я дин мик хотя и близк к ф ктической, но тем не менее не соответствует ей с дост точной точностью.

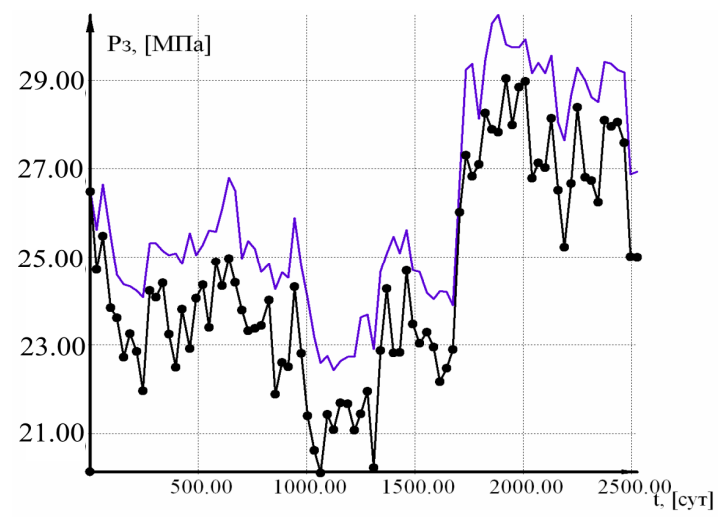

ис. 6. опост вление

р сиетной и ф ктической

дин мик з бойного

д вления без учет

интерференции скв жин

к видно н рис. 7, где сопост влены д вления по той же скв жине с учетом влияния скв жин, н ходящихся в ее окрестности, р счетн я дин мик 3 метно точнее отр ж ет ф ктическую дин мику при н йденных из (13) прониц емостях по линиям интерференции от скв. 534 до 341, 346, 332. рониц емость в исследуемой скв. $534-$ $\mathrm{k}(3 \mathrm{Bc})=218,0$ м . словия орг низ ции процесс вычисления отсек ют дробные ч сти в полученных прониц емостях.

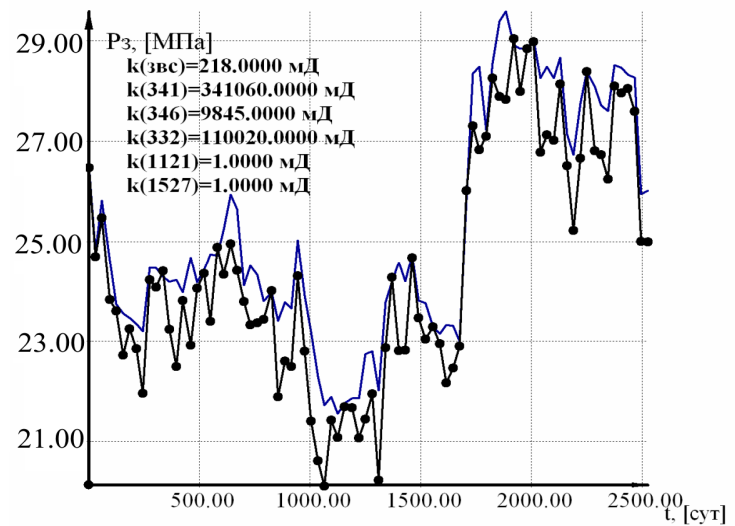

ис. 7. опост вление

р счетной и ф ктической

дин мик 3 бойного

д вления скв. 534 с учетом

интерференции скв жин

сн йденными

прониц емостями

по линиям интерференции

нный метод и соответствующее ему решение (13) имеют несколько ст тистический х р ктер, н личие всплесков д вления может быть и не связ но с р ботой скв жин в окрестности. дн ко здесь не предст вляется возможным отделить ф кторы погрешностей и природных явлений.

примере сопост вления д влений, приведенном н рис. 7, причиной неточного соответствия является интерференция скв. 534 со скв. 346, 341 и 332, смен режимов которых изменяет р счетную и ф ктическую дин мики (рис. 8) в течение 3-х лет с момент пуск скв. 534.

редложенные выше методы н хождения можно отнести к моделям для идентифик ции. о есть предложенную методологию следует отнести к стох стикон литической идентифик ционной модели, т к к к модель включ ет опис ние физических процессов подземной гидромех ники, способ решения относится к ст тистическим метод м.

к видно из вышеприведенного пример (см. рис. 8), решение (13) пок зыв ет большие величины прониц емостей по линиям вз имодействия 534-341, 534-346, 534- 
332, что свидетельствует о н личии в этих зон х к н лов с низким и сверхнизким фильтр ционным сопротивлением.

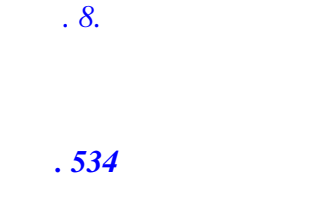

ис. 8. опост вление

р сиетных дин мик

бойногод вления

в н гнет тельной

скв. 534 с учетом и без

учет интерференции

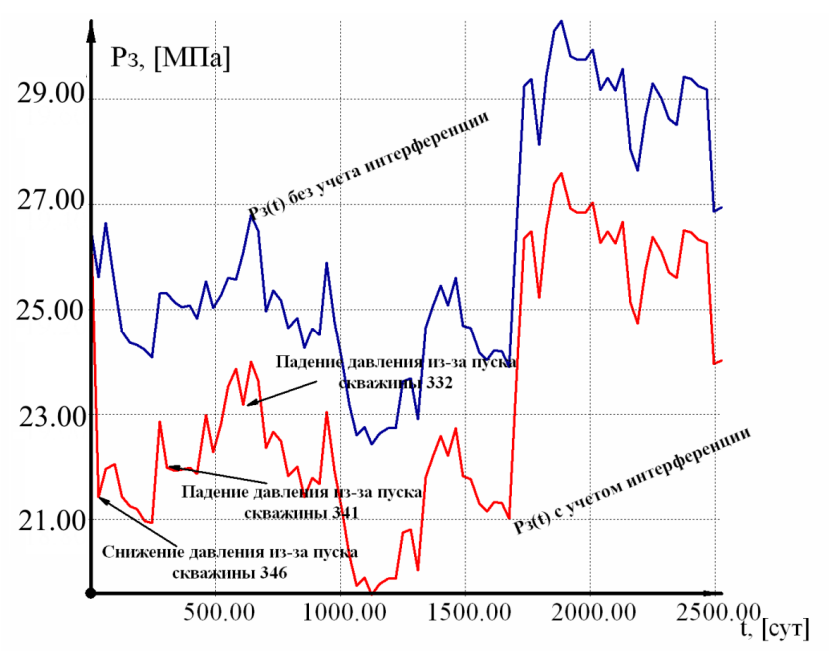

bıводbl

риведенные выше методы идентифик ции прониц емостей и неоднородности пл стов позволяют не только сформиров ть более декв тную модель , но и оптимизиров ть процесс вытеснения посредством ликвид ции или технологического использов ния выявленных ф кторов неоднородности: трещин или к н лов высокой проводимости иной природы.

к честве недост тк предл г емых методов стоит отметить, что метод поиск прониц емостей по линиям интерференции скв жин (13) будет иметь недопустимо большие погрешности при интерв л х р зброс величин д вления менее 0,2 , т к к к т кого род флукту ции могут быть связ ны с погрешностью з меров и вычисления. оэтому для нивелиров ния д нного недост тк и для повышения точности т кой модели необходимо, чтобы режим (величин приемистости) н гнет тельных скв жин периодически изменялся в предел х 20-40 \% в большую или меньшую сторону. о есть т к будет достиг ться генериров ние импульсов (возмущений). кие изменения в режим х р боты н гнет тельных скв жин можно добиться периодической ост новкой или дросселиров нием 3 к чки.

целью снижения погрешности модели со стороны з меров необходимо регистриров ть устьевые д вления и приемистости н гнет тельных скв жин хотя бы р 3 в суТКИ.

основному преимуществу д нной идентифик ционной модели следует отнести в некотором роде однозн чность получ емых результ тов по отношению к тр ссерным исследов ниям. олуч емые по результ т м тр ссерных исследов ний прониц емости между скв жин ми соответствуют к н л м с н ибольшей прониц емостью, которые при этом могут быть весьм м лыми по сечению и не ок зыв ть существенного влияния н процесс вытеснения. олуч емые в ходе решения (13) прониц емости отр ж ют ре льную вз имосвязь между скв жин ми, т к к к они включ ются в величины пьезопроводности.

\footnotetext{
писок литер туры
1. трек лов . видетельство о регистр ции прогр ммы для № 2002611864. омплекс универс льного моделиров ния технических гидр влических систем поддерж ния пл стового д вления (Hydra'Sym). - ., 2002.

2. в стьин . ., трек лов . ., уртов . . н лиз и интерпрет ция дин мики режимов р боты скв жин // еология, геофизик и р зр ботк нефтяных и г зовых месторождений. - . .

3. трек лов . . тем тические модели гидр влических систем для упр вления систем ми поддерж ния пл стового д вления. - юмень: юменский дом печ ти, 2007. - 664 с.

4. трек лов . ., р чев . . рогр ммный комплекс гидродин мического моделиров ния природных и технических систем « емезид идр сим 2014» (Nemesis Hydrasym 2014). видетельство о госуд рственной регистр ции прогр ммы № 2014614505. явк № 2014612343. т гос. регистр ции 28 преля 2014.
} 
5. сниев . ., йруллин . ., мсиев . ., довников . ., йнетдинов Р. Р. нтерпрет ция результ тов г зогидродин мических исследов ний вертик льных скв жин // зов я промышленность. - 2001. - № 3. - . 41-42.

\section{ведения об втор $x$}

р чев ергей в нович, д. т. н., профессор, з ведующий к федрой « зр ботк и эксплу $m$ иия нефтяных и г зовых месторождений», юменский индустри льный университет, тел. 8(3452)283027, e-mail: grachevsi@mail.ru

трек лов лекс ндр л димирович,

д. т. н., профессор, юменский индустри льный университет, г. юмень, тел. 89220040077, e-mail: HYdRASYM@mail.ru

ус инов ртем хирович, к. юменский индустри льный университет, 2. юмень, тел. 89220070151, e-mail: $i Q$ tyumen@mail.ru

\section{Information about the authors}

Grachev S. I., Doctor of Engineering, professor, head of the chair "Development and operation of oil and gas fields», Industrial University of Tyumen, phone: 8(3452)283027, e-mail: grachevsi@mail.ru

Strekalov A. V., Doctor of Engineering, professor, Industrial University of Tyumen, phone: 89220040077, e-mail: HYdRASYM@mail.ru

Khusainov A. T., Candidate of Science in Engineering, associate professor, Industrial University of Tyumen, phone: 89220070151, e-mail: iQtyumen@mail.ru 